\title{
Management of Metastatic Tumours to the Cervical Spine
}

\section{Pawel Zwolak* and Markus Kröber}

Department of Orthopaedics, Trauma and Spine Surgery, Asklepios Klinik Altona, Hamburg, Germany

\begin{abstract}
The spinal column is the most common site of skeletal secondary tumours. Metastatic tumours spreading to spine cause growing problem to the aging population. Patients suffer from immobilizing pain, instability of the spine and secondary neurologic deficits. In most patients treatment is palliative. By improving therapy of tumour-induced instability of the spine and tumour-induced pain, patients' quality of life can be significantly improved and medical costs significantly lowered. In the past, the traditional therapy of metastatic spinal tumours was based on fractionated external beam radiotherapy. Surgical approach was limited to laminectomy (decompression). Nowadays, surgery focuses on preservation and restoration of neurologic function and stability of the spine by marginal resection, and immediate posterior and anterior stabilization. In addition, development of new surgical techniques such as radiofrequency thermoablation and kyphoplasty allowed surgeons address some of the problems related to lytic destruction of the vertebra without increasing morbidity and mortality of the patients associated with open surgery. However, proper treatment of the cervical spine metastases can be achieved only by multidisciplinary team work.
\end{abstract}

Keywords: Metastatic tumours; Cervical spine; Cancer; Kyphoplasty; Vertebroplasty

\section{Introduction}

Autopsy studies demonstrated that about $70 \%$ of cancer patients have spinal metastases at the time of their death [1]. Most of the spinal metastases cause tumour-induced bone pain by release of cytokines; however, not all of them produce neurologic deficits. Only about $10 \%$ of spinal metastases occur in cervical spine [2]. Metastatic spread to spinal column is initially located mostly to posterior half of vertebral body, with later involvement of posterior elements and anterior half of the vertebrae [3].

Only about $50 \%$ of patients with metastatic cancer to bone experience temporary pain relief with current treatment regimens [4]. Treatment focuses on reducing cancer induced osteolysis, decreasing cancer proliferation, addressing cancer-induced instability of the spine and application of powerful opioid pain killers. Reduction of cancer proliferation is achieved with chemotherapy and external beam radiation. Nowadays, local irradiation is considered the most effective therapy for cancer-induced bone pain, with about $50 \%$ of patients experiencing complete pain relief after irradiation. However, most of the patients will have pain relapse to the level before irradiation [5]. It is not known, how local irradiation decreases cancer-induced pain. Some reports suggested that radiation decreased viable tumour mass, and secondary reduced amount of cytokines and growth factors which activated osteoclasts in tumour-bone microenvironment [6,7].

Lung, prostate, breast, and renal malignancies are the most common diagnosed secondary tumours in spinal column $[8,9]$. Surgical treatment is indicated for patients with acute neurological deficits, cancer-induced instability of spinal column, immobilizing pain despite radiotherapy, and life expectancy of at least 3 months $[10,11]$. However, in most cases, it is very difficult to predict accurately life expectancy of patient. In the past, posterior decompression was a standard surgery offered patients with spinal cord compression caused by metastatic tumours. This procedure can effectively increase space for spinal cord, however, with limited impact on neurologic dysfunction and limited value in terms of pain control [9]. Recently, a minimally invasive alternative to open surgery - kyphoplasty has gained greater attention because of good pain control and limited complications rate [3]. The metastatic spread may occur through arterial of venous blood vessels, direct infiltration, and through cerebrospinal fluid. Metastatic tumours mostly affect thoracic and lumbar spine, and relatively rarely migrate to cervical or sacral spine [1]. In contrary to inflammatory entities metastatic cancer do not infiltrate intervertebral discs and do not spread directly to adjacent vertebrae.

\section{Clinical Presentation and Imaging}

Patients with metastatic tumours in cervical spine present with constant insidiously occurring pain. In general pain experienced by the patients can be caused by growth of the metastases (cancer -induced pain), radicular pain - caused by compression of metastatic mass on nerve roots, and mechanical pain produced by instability of cervical spine secondary to metastatic tumour burden [4]. Cancer-induced pain occurs mostly at night, and is not aggravated by ambulation or changing of the position. It is produced by cytokines released from tumour mass in low $\mathrm{pH}$ tumour-environment. These cytokines stimulate osteoklasts to osteolysis, and afferent nerve fibers $[6,7,12]$. This type of pain may be successfully treated with anti-inflammatory drugs. On the other hand the radicular pain is caused by direct compression of tumour mass on nerve roots, and results in pain presenting as a burning or shooting pain in a dermatomal distribution. This pain is treated in most cases with surgical decompression and external beam radiation if the metastatic tumour is radiosensitive.

The mechanical pain is produced by secondary instability caused by tumour burden and loss of structural stability and can be reproduced by ambulation or changing of position (e.g., standing or sitting). It can only be treated with surgery. Growing metastatic tumour may compress directly on spinal cord and cause myelopathy with ataxia, hyperreflexia, clonus, Babinski sign and gait instability. To allow accurate evaluation of tumour extension in cervical spine, it is of great importance to perform proper imaging. Currently, magnetic resonance imaging (MRI) provides excellent information to assess tumour extension in soft tissue [13,14]. Moreover, it provides images which allow surgeon to differentiate whether intra-spinal or nerve root compression is caused

*Corresponding author: Pawel Zwolak, Department of Orthopaedics, Trauma and Spine Surgery, Asklepios Klinik Altona, Paul-Ehrlich-Straße 1, 22763 Hamburg, Germany, Tel: +49401818810; E-mail: paulzwolak@yahoo.com

Received August 10, 2015; Accepted September 03, 2015; Published September 05,2015

Citation: Zwolak P, Kröber M (2015) Management of Metastatic Tumours to the Cervical Spine. J Spine 4: 253.doi:10.4172/2165-7939.1000253

Copyright: $\odot 2015$ Zwolak $\mathrm{P}$, et al. This is an open-access article distributed under the terms of the Creative Commons Attribution License, which permits unrestricted use, distribution, and reproduction in any medium, provided the original author and source are credited. 
by tumour itself or edema. Computed tomography (CT) is an excellent modality to evaluate bony burden caused by the metastatic tumour [15]. However, evaluation of exact soft tissue extension of the tumour and relation to spinal cord may be very limited. On the other hand, CT scan provides very fast information allowing evaluation of the cervical spine stability. In addition, currently used CTs allow 3D-reconstruction and a very good distinction between bony involvements of the posterior cortex vs. soft tissue tumour extension. In patients with posterior instrumentation a CT myelography can provide sufficient information regarding extension of the tumour and compression within spinal canal on spinal cord and nerve roots $[16,17]$. In this patients population MRI or CT scans does not allow exact tumour identification because of artifacts created by screws and rods.

\section{Surgical Treatment}

Surgical approach has changed over last two decades allowing improvement of patients' quality of life as well as improved social functionality. Similarly, as in the past current surgical treatment is mostly palliative. Only patients with solitary metastases, life expectancy more than 1 year, and with slowly growing metastases (e.g. breast, renal cell carcinoma, prostate metastases) [18] may be considered for more radical therapy with wide or marginal resection. In the past, patients with metastatic disease in cervical spine were treated with external beam radiation or posterior decompression [9]. The goal of the surgery was to provide simple procedure to decompress spinal cord and to improve neurologic function [2,9]. However, this type of surgery did not improve pain or local tumour control. Moreover, it did not address the spinal instability and mechanical pain [19]. Some reports demonstrated no benefit of posterior decompression with radiation compared to radiation alone [9]. Current, surgical approach focuses not only on posterior laminectomy for decompression, the goal is to remove the tumour at the compression site to improve local control and neurologic deficits, and to reconstruct the spinal column biomechanics using internal fixation for immediate stabilization [2022]. Of course, level of neurologic recovery depends on duration of neurologic deficits, and progression rate of neurologic decline [19]. Moreover, application of external beam radiation for radiosensitive metastases after surgery may additionally improve neurologic status and ambulatory function of these patients [5]. Treatment with local irradiation is associated with some major complications e.g., wound infections. Risk of developing wound infection is increased because of malnutrition, compromised immunological status in cancer patients as well as preoperative irradiation [23]. New minimally invasive spinal techniques allow us faster recovery after surgery and reduction of postoperative complications related to immobilization (e.g., pneumonia, pulmonary embolism, deep venous thrombosis and wound breakdowns). Vertebroplasty and kyphoplasty have been increasingly used for treatment of cancer induced pain and to reduce the risk of vertebral body collapse [24-29]. Furthermore, addition of radiofrequency ablation to kyphoplasty may improve local control and postpone pain relapse. Cement augmentation with internal fixation can successfully improve atlanto-axial stability after pathologic fracture involving odontoid process [21]. Cement extrusion and embolism are the most common complications associated with kyphoplasty and vertebroplasty, however, they are mostly clinically insignificant. In solitary metastases and slowly growing secondary tumours a corpectomy with cage - (augmented with cement) implantation with plate fixation may offer a curative surgery.

Kyphoplasty with radiofrequency ablation provide excellent alternative to open procedures in local control of the metastatic tumour, and biological, and axial pain control. The patients can be very fast mobilized on the word and can early start palliative chemotherapy or postoperative local irradiation.

\section{Conclusion}

The aging population and increasing number of patients with metastatic spine disease is a challenging medical problem in many industrialized countries. With new medical developments it was possible to improve survival of cancer patients and quality of life. However, symptomatic patients with metastatic spread to cervical spine often require complex multidisciplinary approach. Precise clinical history and imaging are the clue to proper and rash diagnosis, and treatment of these patients before neurological deficits occurred. Because of that, it is of great importance to involve in this complex multidisciplinary treatment, also general practitioners, referring orthopaedic specialists and trained nurses. These primary care managers have an important role in initial selection of patients based of their clinical history and symptoms, and their further referral to specialized spine centers. Ciccone et al. published very interesting results using Leonardo project to show the feasibility of cooperation between; specially trained nurses, general practitioners and referring specialists in the management of patients with heart failure and diabetes [30]. These results suggest that similar cooperation of primary care managers with specialized spine centres could improve the management of patients with metastatic tumours to the cervical spine (Figure 1). These patients population

patients with new neck pain or

already diagnosed cervical spine metastasis

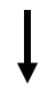

general practitioners, specially trained nurses, and referring specialists

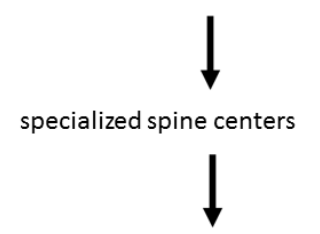

general practitioners, specially trained nurses, and referring specialists

\author{
clinical history, first imaging \\ and diagnosis \\ imaging and treatment: \\ - spine surgery \pm \\ - radiotherapy \pm \\ - chemotherapy \pm \\ - brace \\ patient care after \\ discharge from hospital
}

Figure 1: Algorithm for care management of patients with metastatic tumors to the cervical spine. 
could be faster diagnosed and referred to specialized spine centres for the treatment. In addition, it would improve the quality of care of patients after discharge from hospital.

Surgical treatment is mostly palliative and does not prolong survival. However, it improves neurological deficits, stability of the spine and improves cancer-induced bone pain, radicular and mechanical pain. These surgical goals have major impact on patients' social functionality and quality of life.

\section{Competing Interests}

The authors declare that they have no competing interests.

\section{References}

1. Galasko CS (1995) Diagnosis of skeletal metastases and assessment of response to treatment. Clin Orthop Relat Res : 64-75.

2. Ryken TC, Eichholz KM, Gerszten PC, Welch WC, Gokaslan ZL, et al. (2003) Evidence-based review of the surgical management of vertebral column metastatic disease. Neurosurg Focus 15: E11.

3. Farrokhi M, Nouraei H, Kiani A (2012) The Efficacy of Percutaneous Vertebroplasty in Pain Relief in Patients with Pathological Vertebral Fractures due to Metastatic Spinal Tumors. Iran Red Crescent Med J 14: 523-530.

4. Meuser T, Pietruck C, Radbruch L, Stute P, Lehmann KA, et al. (2001) Symptoms during cancer pain treatment following WHO-guidelines: a longitudinal followup study of symptom prevalence, severity and etiology. Pain 93: 247-257.

5. Tong D, Gillick L, Hendrickson FR (1982) The palliation of symptomatic osseous metastases: final results of the Study by the Radiation Therapy Oncology Group. Cancer 50: 893-899.

6. Hoskin PJ, Stratford MR, Folkes LK, Regan J, Yarnold JR (2000) Effect of local radiotherapy for bone pain on urinary markers of osteoclast activity. Lancet 355: 1428-1429.

7. Goblirsch M, Mathews W, Lynch C, Alaei P, Gerbi BJ, et al. (2004) Radiation treatment decreases bone cancer pain, osteolysis and tumor size. Radiat Res 161: 228-234.

8. Aebi M (2003) Spinal metastasis in the elderly. Eur Spine J 12 Suppl 2: S202213

9. Young RF, Post EM, King GA (1980) Treatment of spinal epidural metastases. Randomized prospective comparison of laminectomy and radiotherapy. $J$ Neurosurg 53: 741-748.

10. Fourney DR, Gokaslan ZL (2004) Anterior approaches for thoracolumbar metastatic spine tumors. Neurosurg Clin N Am 15: 443-451.

11. Polly DW Jr, Chou D, Sembrano JN, Ledonio CG, Tomita K (2009) An analysis of decision making and treatment in thoracolumbar metastases. Spine (Phila Pa 1976) 34: S118-127.

12. Zwolak P, Dudek AZ, Bodempudi VD, Nguyen J, Hebbel RP, et al. (2008) Local irradiation in combination with bevacizumab enhances radiation control of bone destruction and cancer-induced pain in a model of bone metastases. Int $\mathrm{J}$ Cancer 122: 681-688.

13. Colman LK, Porter BA, Redmond J 3rd, Olson DO, Stimac GK, et al. (1988) Early diagnosis of spinal metastases by CT and MR studies. J Comput Assist Tomogr 12: 423-426.

14. Plank C, Koller A, Mueller-Mang C, Bammer R, Thurnher MM (2007) Diffusionweighted MR imaging (DWI) in the evaluation of epidural spinal lesions. Neuroradiology 49: 977-985.

15. Redmond J 3rd, Spring DB, Munderloh SH, George CB, Mansour RP, et al (1984) Spinal computed tomography scanning in the evaluation of metastatic disease. Cancer 54: 253-258.
16. Grossman SA, Weissman DE, Wang H, Gilbert MR, Updike ML, et al. (1990) Early diagnosis of spinal epidural metastases using out-patient computed tomographic myelography. Eur J Cancer 26: 495-499.

17. Ahlhelm F, Schulte-Altedorneburg G, Naumann N, Nabhan A, Reith W (2006) [Imaging of extradural spinal lesions]. Radiologe 46: 1035-1043.

18. Cereceda LE, Flechon A, Droz JP (2003) Management of vertebral metastases in prostate cancer: a retrospective analysis in 119 patients. Clin Prostate Cancer 2: 34-40.

19. Abrahm JL, Banffy MB, Harris MB (2008) Spinal cord compression in patients with advanced metastatic cancer: "all I care about is walking and living my life". JAMA 299: 937-946.

20. Gokaslan ZL, York JE, Walsh GL, McCutcheon IE, Lang FF, et al. (1998) Transthoracic vertebrectomy for metastatic spinal tumors. J Neurosurg 89 599-609.

21. Zwolak P, Kröber M (2015) Acute neck pain caused by atlanto-axial instability secondary to pathologic fracture involving odontoid process and $\mathrm{C} 2$ vertebral body: treatment with radiofrequency thermoablation, cement augmentation and odontoid screw fixation. Arch Orthop Trauma Surg 135: 1211-1215.

22. Finkelstein JA, Zaveri G, Wai E, Vidmar M, Kreder H, et al. (2003) A populationbased study of surgery for spinal metastases. Survival rates and complications. J Bone Joint Surg Br 85: 1045-1050.

23. Zwolak P, König MA, Osterhoff G, Wilzeck V, Simmen HP, et al. (2013) Therapy of acute and delayed spinal infections after spinal surgery treated with negative pressure wound therapy in adult patients. Orthop Rev (Pavia) 6: 5(4): e30.

24. Monterumici DA, Narne S, Nena U, Sinigaglia R (2007) Transoral kyphoplasty for tumors in C2. Spine J 7: 666-670.

25. Lykomitros V, Anagnostidis KS, Alzeer Z, Kapetanos GA (2010) Percutaneous anterolateral balloon kyphoplasty for metastatic Iytic lesions of the cervical spine. Eur Spine J 19: 1948-1952.

26. Fourney DR, Schomer DF, Nader R, Chlan-Fourney J, Suki D, et al. (2003) Percutaneous vertebroplasty and kyphoplasty for painful vertebral body fractures in cancer patients. J Neurosurg. 98: 21-30.

27. Bateman AH, Way AC (2015) Corpectomy with adjacent-level kyphoplasty to treat metastatic lung cancer in three contiguous cervical vertebrae causing focal neurologic compromise. Global Spine J 5: 140-143.

28. Blondel B, Litré F, Graillon T, Adetchessi T, Dufour H, et al. (2013) Metastatic odontoid fracture management by anterior screw fixation and kyphoplasty. Neurochirurgie 59: 191-194.

29. Druschel C, Schaser KD, Melcher I, Haas NP, Disch AC (2011) Minimally invasive combined anterior kyphoplasty for osteolytic C2 and C5 metastases. Arch Orthop Trauma Surg 131: 977-981.

30. Ciccone MM, Aquilino A, Cortese F, Scicchitano P, Sassara M, et al. (2010) Feasibility and effectiveness of a disease and care management model in the primary health care system for patients with heart failure and diabetes (Project Leonardo). Vasc Health Risk Manag 6: 297-305. 